\title{
Effect of Home Care Service on the Quality of Life in Patients with Gynecological Cancer
}

\author{
Demet Aktas ${ }^{1 *}$, Fusun Terzioglu ${ }^{2}$
}

\begin{abstract}
The purpose of the research was to determine the effect of home care service on the quality of life in patients with gynecological cancer. This randomized case control study was carried out in a womans hospital between September 2011 and February 2012. Women undergoing gynecological cancer treatment were separated into intervention and control groups, of 35 patients each. The intervention group was provided with nursing care service through hospital and home visits $\left(1^{\text {st }}, 12^{\text {th }}\right.$ weeks) within the framework of a specifically developed nursing care plan. The control group was monitored without any intervention through the hospital routine protocols $\left(1^{\text {st }}, \mathbf{1 2}^{\text {th }}\right.$ weeks). Data were collected using An Interview Form, Home Visit Monitoring Form and Quality of Life Scale/Cancer Survivors. Effects of home care service on the quality of life in gynecological cancer patients were investigated using chi-square tests, McNemar's test, independent t-test and ANOVA. This study found that the intervention group receiving home care service had a moderately high quality of life (average mean: 6.01 \pm 0.64 ), while the control group had comparatively lower quality (average mean: $4.35 \pm 0.79$ ) within the 12 week postdischarge period $(\mathbf{p}<0.05)$. This study found home care services to be efficient in improving the quality of life in patients with gynecological cancer.
\end{abstract}

Keywords: Gynecological cancer - home care service - home visit - nursing interventions - quality of life

Asian Pac J Cancer Prev, 16 (9), 4089-4094

\section{Introduction}

After breast cancer, gynecologic cancers are the most common female cancers (Mantegna et al., 2013). Among all the female cancers, they have a share of $9 \%$ and 11.9\% in America and Turkey, respectively (Siegel et al., 2013). Such cancers directly affect female genital organ functions, so they may damage body image, self-esteem and sexual identity (Knapstein et al., 2004; Keskin and Gumus, 2011).

Women suffer many physical and social problems in addition to the psychological and sexual ones caused by gynecological cancer. The primary problems are physical issues that significantly complicate daily life activities, and reduce quality of life during the treatment process (Francisca et al., 2007; Akkuzu et al., 2012; Palmer and Gillespie, 2012). Pain, fatigue, nausea/vomit, constipation/ diarrhea and dermal changes are the physical problems that were most commonly reported in the course of treatment (Kuzeyli Yıldırım, 2006; Ertem, 2010). The patients may however experience such psychosocial troubles as loneliness, social isolation (Distefano et al., 2008), fear of death and depression during the advanced steps of the treatment process (average 6 to 12 weeks) (Lowdermilk, 2006; Distefano et al., 2008). Such psychosocial problems can persist for longer than two years in 55\% of women, hence reducing their quality of life (Distefano et al., 2008; Sharifa et al., 2014). Gynecological cancer treatments cause a number of changes in the body image of women (organ loss, scar tissue, etc.) (Unsar et al., 2007), and adversely affect their sexuality (loss of sexual desire, decrease in sexual intercourse, loss sexual attractiveness, anorgasmia, etc), resulting in a reduced quality of life (Yajima et al., 2001; Jocham et al., 2009; Demirtas and Pinar, 2014).

These patients have an increasing demand for professional health care services to efficiently overcome all the problems that may develop in the treatment process. To satisfy the patients' demand for health care services, it is of high importance that health care service beginning at the hospital continues post-discharge in the form of home care service. Many studies found that patients with gynecological cancer receiving home care service had apparently better physical (Lowdermilk, 2006; Ahlner-Elmqvist et al., 2008; Sharifa et al., 2014), and psychological health (effective coping) compared to healthy patients (Horton, 2002; Molassiotis et al., 2009; Mantegna et al., 2013), and fewer sexual problems developed in the three months following cancer treatments (McCorcle et al., 2009; Bakitas et al., 2009). Also, their social lives (interpersonal communication, etc.) were positively affected and their quality of life was improved 
(Ahlner-Elmqvist et al., 2008; Jocham et al., 2009; Bakitas et al., 2009). Furthermore, home care service was determined to decrease the time of hospitalization, risk of hospital infection (McCorcle et al., 2000; Lowdermilk, 2006), and frequency of repeated hospital visits by 50 percent, which may also be effective in improving the quality of life in patients with cancer (Hırabayashi et al., 2007).

There is a need for professional nursing care for patients with gynecological cancer to provide efficient home care service and improve the quality of life in patients. A quality, continuous and proven home care service rendered by nurses would be efficient in preventing and reducing any possible problems that can develop in the patients. In this context, the nurses should adopt a multidisciplinary approach to evaluate patients in a comprehensive manner, and develop a specific home care plan for each individual patient. Such planning should be developed by taking into consideration patient nutrition, movement, ventilation, drug management, basic physical care, pain management, and training/consultancy activities (Ertem et al., 2009; Palmer and Gillespie, 2012). It is clear that this health service would be effective for patients with gynecological cancer to help them cope with the problems that may develop in association with the treatments, as well as for shortening the time of hospitalization, reducing frequency of repeated hospital visits, and significantly enhancing the quality of life in patients.

Purpose of the study was to determine the effect of home care service on the quality of life in patients with gynecological cancer.

\section{Materials and Methods}

The research is carried out at the gynecology-oncology clinic of a woman hospital on 01 September 2011 and 30 February 2012. The study group consisted of women who were hospitalized and treated for the diagnosis of ovarian, endometrial and cervical cancer. The inclusion criteria were: (a) the patient should be operated for the gynecological cancer for the first time, (b) the patient should be of the maximum level III as of the patient cycle, (c) the patient should undergo chemotherapy or radiotherapy, (d) the patient should be sexually active, (e) the patient should be able to understand and respond the asked questions, (f) the patient should not have any psychiatric disorder. Randomised sampling method was used. The sample size was determined based on a previous study conducted by Maughan in 2008. Based on this, the sample size was calculated as 35 for each group, by using $\alpha=0.05$ and power $=0.70$ to determine the difference of two independent groups and 35 patients were taken to each of the intervention and control groups. The power of the research after study was determined to be power $=0.95$.

The data were collected by using An Interview Form (12 items), Home Visit Monitoring Form (49 items) and Quality of Life Scale/Cancer Survivors (QOL-CS). QOLCS was revised by Ferrell et al. in 1995. The reliability and validity of the Turkish adaptation of the scale was carried out by Reis et al. (2010). The QOL-CS consist of 41 items that elicit QOL-CS information on four subscales; physical, psychological, social and spiritual well-being ones. Participants rate each item "based on your life at this time" on a 10-point scale with polar opposite phrases at either end (e.g., "worst" or "best"). A high total point indicates that the patient has a high life quality, and vice versa. The scale is interpreted as follows: $0-2$ points worst; 3-4 points moderately low; 5-6 points moderately high; 7-8 points better; and 9-10 points best (Reis et al., 2010). This scale and two different forms were used for the both research groups in certain time intervals. The groups and their interventions are shown in Table 1.

The intervention group patients were first seen at the time of their admission in the gynecology-oncology clinic, and the subsequently rendered nursing care services (pre/postoperative care and discharge teaching (DT) in line with the Nursing Care Plans (NCP) were developed within the period of hospitalization. Post-discharge home visits were made to the intervention group patients in the $1^{\text {st }}$ and $12^{\text {th }}$ weeks. Rendered home care services in line with the nursing care plans (wound care, drug and pain management, resolving of physical, psychological and social problems, nutrition, medication management etc.) were developed within the discharge monitoring period of 12 weeks, and the prepared "cancer patient teaching guideline" was presented. The home visits was determined using the applications in the literature (Maughan, 2008; Ertem et al., 2009; Seavarsdottir and Fridriksdottir, 2006; Turgut et al., 2012). Each visit lasted approximately 60 to 90 minutes in the intervention group. With the control group patients, the first interviews took place upon their admission to the hospital, and they were monitored by the researcher in line with routine hospital procedures that involved no intervention. The patients of this group were visited at home in the 1st and 12th weeks to determine if any problems had developed, and were dispatched to a healthcare facility if necessary. Each visit lasted approximately 30 minutes in the control group.

The data were collected after the approval of the Turgut Ozal University Clinical Research Ethical Committee.

Table 1. Patient Groups and their Interventions

\begin{tabular}{|c|c|c|c|c|c|c|c|c|c|c|c|c|}
\hline \multirow{3}{*}{$\begin{array}{l}\text { Monitering period } \\
\text { Patient groups }\end{array}$} & \multicolumn{5}{|c|}{ Pre-Discharge } & \multicolumn{6}{|c|}{ Post-Discharge (Home visits) } & \multirow{3}{*}{$\mathrm{n}$} \\
\hline & \multicolumn{3}{|c|}{ Pre-op. } & \multicolumn{2}{|c|}{ Post-op. } & \multicolumn{3}{|c|}{$1^{\text {th }}$ week home visits } & \multicolumn{3}{|c|}{$12^{\text {th }}$ week home visits } & \\
\hline & $\overline{\mathrm{IF}}$ & QOL & $\mathrm{NCP}$ & $\overline{\mathrm{NCP}}$ & $\overline{\mathrm{DT}}$ & $\overline{\mathrm{HVM}}$ & $\mathrm{NCP}$ & $\overline{\mathrm{QOL}}$ & $\overline{\mathrm{HVM}}$ & $\mathrm{NCP}$ & $\overline{\mathrm{QOL}}$ & \\
\hline Intervention group & + & + & + & + & + & + & + & + & + & + & + & 35 \\
\hline $\begin{array}{l}\text { Control group } \\
\text { Total }\end{array}$ & + & + & - & - & - & + & - & + & + & - & + & $\begin{array}{l}35 \\
70\end{array}$ \\
\hline
\end{tabular}

*Pre-op.:Pre-operational stage; Post-op.: Post-operational stage; IF: An Interview Form; QOL: Quality of Life Scale/Cancer Survivors; NCP: The Nursing Care Plans; DT: Discharge Teaching; HVM: Home Visit Monitoring Form 
Prior to the data collection, informed consent of all patients were obtained. The patients were informed about the purpose of the research study, what would be done to them if they were to participate and that they had the right to quit the study whenever they wanted throughout the process and they were also informed about whether they refused to participate in the research study or quit after accepting to participate, the healthcare they were already getting would not be affected in any way.

The Statistical Package for Social Sciences (SPSS) version 11.5 (PD Anatolia Research Consulting and Education Ltd., SPSS Statistics 19, Serial: 10240711) was used for the data management, and chi-square test, Mc-Nemar test, Student's t-tests and one-way analysis of variences were used for the analysis.

\section{Results}

The average age of patients in the intervention and control group was $49.3 \pm 1.70$ years. In both groups, $85.7 \%$ of patients were primary school graduates. $44.3 \%$ of them suffered from stage II or III ovarian cancers and $62.9 \%$ underwent abdominal gynecological surgery and chemotherapy. Radical hysterectomy (type III) was applied in $91.4 \%$ of them (Table 2).

Within the monitoring period (for the first 12 weeks through post-discharge) it was found during home visits that the "loss of sexual attractiveness" problem was $42.9 \%$ and $20 \%$ in the control and intervention groups, respectively, and such difference was considered statistically significant between the two groups $(p<0.05$; Table 3). Within the same period of monitoring through post-discharge home visits for the first 12 weeks, the control and intervention groups also showed a significant statistical difference with respect to experience of the "deficient/defective feeling" problem, with rates of $51.4 \%$ and $37.1 \%$ in the control and intervention groups, respectively $(\mathrm{p}<0.05$; Table 3$)$.

In the present study, within the post-discharge monitoring period of 12 weeks, it was found that the intervention group patients receiving home care service had

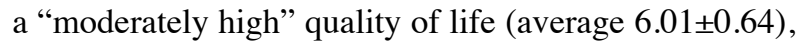
while the control group subjects had a relatively lower quality of life (average $4.35 \pm 0.79$ ), with a statistically significant difference between the two groups $(p<0.05$; Figure 1). Within the post-discharge monitoring period of 12 weeks, the intervention group patients receiving home care service had a "better" physical well-being (average 7.42 \pm 0.99 ), while the control group subjects had a relatively lower quality of life (average 5.32 \pm 1.17 ) with a statistically significant difference between the two groups $(\mathrm{p}<0.05)$. Within the same period, the intervention

Table 2. Demographic and Disease Characteristics of Participants

\begin{tabular}{|c|c|c|c|c|c|c|c|}
\hline & & \multicolumn{4}{|c|}{ Groups } & \multicolumn{2}{|c|}{ Statistical Analysis } \\
\hline \multirow{2}{*}{\multicolumn{2}{|c|}{ Some characteristics of patients }} & \multicolumn{2}{|c|}{$\begin{array}{l}\text { Intervention Group } \\
\qquad(\mathrm{n}=35)\end{array}$} & \multicolumn{2}{|c|}{$\begin{array}{c}\text { Control Group } \\
(n=35)\end{array}$} & \multirow[b]{2}{*}{ chi-square } & \multirow[b]{2}{*}{ P-value } \\
\hline & & $\mathrm{n}$ & $\%$ & $\mathrm{n}$ & $\%$ & & \\
\hline \multirow[t]{2}{*}{ Education level } & Primary+secondary & 30 & 85.7 & 30 & 85.7 & 0.001 & 1 \\
\hline & Higher education & 5 & 14.3 & 5 & 14.3 & & \\
\hline \multirow[t]{3}{*}{ Cancer type } & Ovarian & 15 & 42.9 & 16 & 45.8 & 0.266 & 0.875 \\
\hline & Endometrial & 15 & 42.9 & 13 & 37.1 & & \\
\hline & Cervical & 5 & 14.2 & 6 & 17.1 & & \\
\hline \multirow[t]{3}{*}{ Disease Stage } & Stage 1 & 5 & 14.3 & 3 & 8.6 & 0.823 & 0.663 \\
\hline & Stage 2 & 14 & 40 & 17 & 48.6 & & \\
\hline & Stage 3 & 16 & 45.7 & 15 & 42.8 & & \\
\hline \multirow[t]{2}{*}{ Type of therapy } & Surgery+ radiotherapy & 13 & 37.1 & 13 & 37.1 & 0.001 & 1 \\
\hline & Surgery+ chemotherapy & 22 & 62,9 & 22 & 62.9 & & \\
\hline \multirow[t]{2}{*}{ Surgical operation } & Type III hysterectomy ${ }^{1}$ & 32 & 91.4 & 32 & 91.4 & 0.001 & 1 \\
\hline & Type II hysterectomy² & 3 & 8.6 & 3 & 8.6 & & \\
\hline Total & & 35 & 100 & 35 & 100 & & \\
\hline
\end{tabular}

${ }^{* 1}$ Radical hysterectomy (type III); ${ }^{2}$ Modified radical hysterectomy (type II)

Table 3. Changes in Body Image of Participants after Operation

\begin{tabular}{|c|c|c|c|c|c|c|c|c|c|c|}
\hline \multirow{3}{*}{$\begin{array}{l}\text { Some Changes in body } \\
\text { image of participants }{ }^{1}\end{array}$} & \multicolumn{10}{|c|}{ Monitoring Periods } \\
\hline & \multicolumn{3}{|c|}{ Pre-Discharge } & \multicolumn{3}{|c|}{$1^{\text {st }}$ week } & \multicolumn{3}{|c|}{$12^{\text {th }}$ week } & \multirow{2}{*}{$\begin{array}{c}\text { Statistical analysis. } \\
\qquad \text {-value }\end{array}$} \\
\hline & $\mathrm{n}$ & $\%$ & $\mathrm{p}$ & $\mathrm{n}$ & $\%$ & $\mathrm{p}$ & $\mathrm{n}$ & $\%$ & $\mathrm{p}$ & \\
\hline Lost sexually & & & 0.232 & & & 0.013 & & & 0.039 & 0.041 \\
\hline \multicolumn{11}{|l|}{ attractiveness } \\
\hline İntervention $(\mathrm{n}=35)$ & 15 & 42.9 & & 8 & 22.9 & & 7 & 20.0 & & \\
\hline Control $\quad(n=35)$ & 20 & 57.1 & & 18 & 51.4 & & 15 & 42.9 & & \\
\hline \multicolumn{11}{|l|}{ Deficient/defective feeling } \\
\hline İntervention $(\mathrm{n}=35)$ & 4 & 11.4 & 0.006 & 15 & 42.9 & 0.631 & 13 & 37.1 & 0.229 & 0.047 \\
\hline Control $\quad(n=35)$ & 14 & 40.0 & & 17 & 48.6 & & 18 & 51.4 & & \\
\hline
\end{tabular}

*1This question was answered by the women who reported to have experienced following changes in their body image; $P$-value; Mc-Nemar Test was used (Pre-discharge to 12 th week) 
Demet Aktas and Füsun Terzioglu

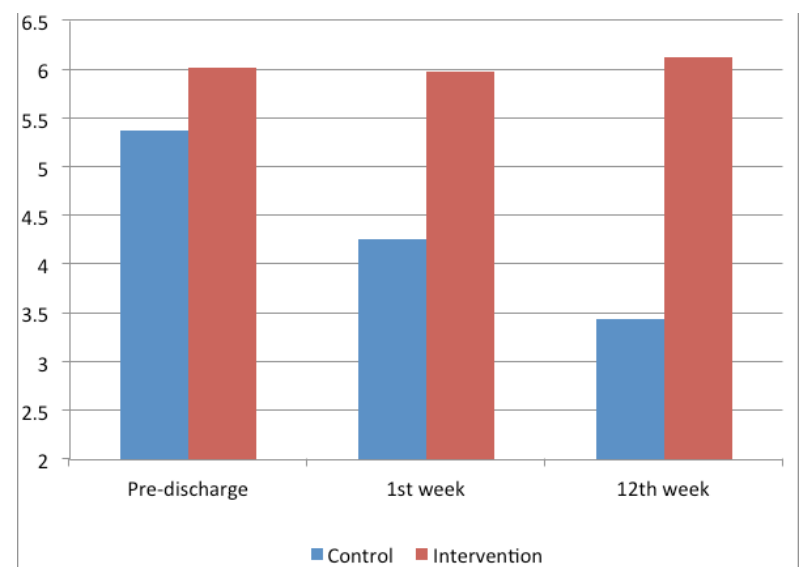

Figure 1. Quality of Life Outcomes of Intervention and Control Groups

group was found to have a "moderately high" social wellbeing (average 6.61 \pm 1.07 ), compared to the lower level of social well-being (average 5.15 \pm 2.07 ) reported for the control group $(\mathrm{p}<0.05)$. As for the spiritual well-being within the same period, the intervention group patients had a "moderately high" quality of life (average 5.23 \pm 1.13 ), while the control group subjects had a relatively lower quality of life (average 3.50 \pm 0.80 ) with a statistically significant difference between the two groups $(\mathrm{p}<0.05)$. Within the post-discharge monitoring period of 12 weeks, the intervention group patients receiving home care service had a "moderately high" psychological well-being (average 5.23 \pm 1.13 ), while the control group subjects had a relatively lower quality of life (average 3.50 \pm 0.80 ) $(\mathrm{p}<0.05)$.

The intervention group patients receiving home care service were observed to experience fewer physical problems such as abdominal distension, immobilization, insomnia and fatigue than the control group patients within the pre-operative period and 12 week post-discharge period $(\mathrm{p}<0.05)$. Similarly, the intervention group were reported to have less psychosocial problems such as difficulty in coping with, loneliness and changes in role performance within the pre-operative period and 12 week post-discharge period $(\mathrm{p}<0.05)$.

\section{Discussion}

While gynecological cancers are becoming more commonly encountered across the world, the rate of mortality is gradually being reduced with the advanced early diagnosis-treatment methods introduced by developed countries (Akkuzu, 2012; Siegel et al., 2013). This decrease in the rate of mortality for gynecological cancers results in a longer-term struggle for the patients who must live with a chronic illness accompanied by many troubles and problems, and it considerably reduces the quality of life in patients (Turgut et al., 2012; Mantegna et al., 2013). One of the most important negative effects on quality of life caused by gynecological cancer treatments is the change in the women's body image (Francisca et al., 2007); Reis et al., 2010; Keskin and Gumus, 2011). Body image encompasses the self-image, skills, limitations and perceptions of an individual, and makes it possible for her to perceive herself as tall or short, beautiful or ugly (Turgut et al., 2012). The loss of female genital organs (e.g. uterus) considerably damages the body image (Sacerdoti et al., 2010; Demirtas and Pınar, 2014). In the present study results revealed that, for the 12 week monitoring period, in the intervention group patients receiving home care service such problems as the lack of sexual self-esteem and deficient/defective feeling, was two-fold lower than the control group patients who did not receive home care service. Previous studies reported that the loss of reproductive organs following the treatment of gynecological cancer cause patients to feel deficient/ defective and to experience a loss of sexual attractiveness, so that the quality of life is reduced (Saevarsdottir et al., 2010; Xie et al., 2013). In a study reported by Sacerdoti et al. (2010), it is reported that the home care service for patients with gynecological cancer is effective in solving wrong perceptions of body image, and aids in the development of a positive body image. Hirabayaski et al. (2007) reported that the home care service for patients with gynecological cancer facilitated the patient's selfsatisfaction and the ability to check on the operative injury in the early post-discharge period, while McCorcle et al. (2009) reported that it was effective in gaining a positive body image.

The gynecological cancer treatment process may negatively affect the individual and family's quality of life to a considerable extent in all respects. In the current study, we found that the intervention group patients receiving home care services within the first 12 week post-discharge monitoring period had a moderately high quality of life, while the control group patients had a considerably lower quality of life. In the literature, it is reported that the quality of life of patients with gynecological cancer is reduced during the treatment process (Reis et al., 2010; Mishra, 2011; Akkuzu,2012). Previous research studies reported that the cancer patients receiving home care have a considerably higher quality of life compared to that of the cancer patients who do not receive any home care service (Ahlner-Elmqvist et al., 2008; Jocham et al., 2009; Fauci et al., 2012).

When one evaluates the sub-dimensions of the QOLCS scale used for our study, it is understood that the intervention group patients have a higher physical wellbeing than the control group within the 12 week postdischarge period. It was found that "fatigue" was the most important problem affecting the physical health in both groups. Furthermore, the problem of fatigue in the control group patients was accompanied with such other problems as anorexia, insomnia and pain. Saevarsdottir et al. (2010) reported that patients commonly experienced fatigue in the process of gynecological cancer treatment, while Rannestad et al. (2007) reported the frequent experience of such problems as pain and insomnia. Home care service may prevent the development of such physical problems, resulting in an improved quality of life in patients (Cigna, 2007; Ertem, 2010; De Raaf et al., 2013).

Our study found that the sub-dimension of the QOLCS scale most affected was psychological well-being. In the 12 week post-discharge monitoring period, the control group patients had a very low psychological well- 
being compared to that of the intervention group patients receiving home care service. In both groups, the patients were found to experience such psychological problems as recurrence of cancer, spreading (metastasis) of cancer and the development of a secondary cancer. Similar results were obtained from some other studies (Bakitas et al., 2009; Reis et al., 2010; De Raaf et al., 2013), and the gynecological cancer patients receiving home care were found to have apparently better psychological health with their quality of life being improved (Zimmermann et al., 2014).

Within the 12 week post-discharge monitoring period, the intervention patients receiving home care were found to have a higher social well-being than the control group. Family stress and sexuality were found to be the most important problems affecting the social well-being in both of the patient groups. Reis et al. (2010) reported that the gynecological cancer patients had a moderately high social well-being, while the studies reported by Jocham et al. (2009) and Ertem et al. (2009), found that sexuality and family stress were the most important issues affecting social well-being, which supports our findings. Palmer and Gillespie (2012) and Cigna (2007) reported that home care service had an important role in solving the social well-being problems in gynecological cancer patients. It is reported that the patients with gynecological cancer receiving home care services develop less social problems, and have a higher quality of life compared to those who do not receive home care service (Turgut et al., 2012; Zimmermann et al., 2014).

This study found that the control group patients had lower spiritual well-being than the intervention group receiving home care services in the 12 week postdischarge monitoring period. In the women included in the intervention group receiving home care it was determined that hopeful future expectations positively affected their spiritual well-being. Kelleci (2005) pointed out that the hopeful future expectation was important in enhancing the quality of life of patients with cancer. It was confirmed by a number of studies that home care service was effective in ensuring the hopeful future expectation, as well as disease adaptation, and emotional well-being by worship, whereby the quality of life of the patient with cancer was improved (Saevarsdottir et al., 2010; Mishra, 2011).

In the 12-week post-discharge monitoring period following the preoperative period, such problems as abdominal distension, fatigue, immobilization and insomnia were found to be two-fold higher in the control group patients than those of the intervention group. De Raaf et al. (2012) found that home care service significantly reduced the development of such problems in patients with cancer, while Mishra (2011) reported that home care service resulted in an improved quality of life in the patients by diminishing their physical problems.

This study found that such problems as the difficulty in coping with, loneliness and changes in role performance were two-fold more prominent in the control group patients compared to the intervention group within the preoperative to 12 week post-discharge monitoring period. It is reported in the literature that patients receiving home care service are more successful in overcoming problems that develop, have stronger sharing within their social environment, and enjoy an improved quality of life compared to those who do not receive any home care service (Distefano et al., 2008; Ertem, 2010).

In conclusion, this study found home care services to be efficient in improving the quality of life in patients with gynecological cancer. Furthermore, the home care service was found to be effective in both prevention and solution of the problems experienced by the patients during the treatment process. Also, it was determined through the post-discharge home visits that during the first 12-week monitoring period such problems as loss of sexual attractiveness, deficient/defective feelings, abdominal distension, immobilization, insomnia, fatigue, difficulty in coping with, loneliness and changes in role performance were more prominent in the control group in comparison with the intervention group. These results indicate that the nurses may have an important role in improving the quality of life in patients by means of active participation in the home care service of patients with gynecological cancer.

\section{Acknowledgements}

Abstract of the present study was presented via oral presentation in 17 th International Nursing Research Conference (Spain, Lleida).

\section{References}

Ahlner-Elmqvist M, Jordhøy MS, Bjordal K, Jannert M, Kaasa S (2008). Characteristics and Quality of Life of Patient Who Choose Home Care at the End of Life. J Pain Symptom Manage, 36, 217-27.

Akkuzu G (2012). An evaluation of the quality of life of women undergoing chemotherapy due to a diagnosis of a gynecological oncological disease. Asian Pac J Cancer Prev, 13, 1277-80.

Bakitas M, Lyons KD, Hegel MT, et al (2009). Effects of a palliative care intervention on clinical outcomes in patients with advanced cancer: the Project ENABLE II randomized controlled trial. JAMA, 302, 741-49.

Cigna JA (2007). Home care physical therapy for the cancer patient. J Home Healthc Nurs, 25, 158-61.

De Raaf PJ, De Klerk C, Timman R, et al (2013). Systematic monitoring and treatment of physical symptoms to alleviate fatigue in patients with advanced cancer: a randomized controlled trial. J Clin Oncol, 31, 716-23.

Demirtas B, Pınar G (2014). Determination of sexual problems of turkish patients receiving gynecologic cancer treatment: a cross-sectional study. Asian Pac J Cancer Prev, 15, 6657-63.

Distefano M, Riccardi S, Capelli G, et al (2008). Quality of life and psychological distress in locally advanced cervical cancer patients administered pre-operative chemoradiotherapy. J Gynecol Oncol, 111, 144-50.

Ertem G (2010). Jinekolojik kanserlerde evde bakım. Turk Onkoloji Dergisi, 25, 124-32.

Ertem G, Kalkım A, Bulut S, Sevil U (2009). Radyoterapi alan hastaların evde bakım gereksinimleri ve yasam kaliteleri. Maltepe Universitesi Hemsirelik Bilim ve Sanatı Dergisi, 2, 4-12.

Fauci J, Schneider K, Walters C, et al (2012). The utilization of palliative care in gynecologic oncology patients near the end of life. Gynecol Oncol, 127, 175-9.

Ferrell BR, Dow RH, Grant M (1995). Measurement of the 
Demet Aktas and Füsun Terzioglu quality of life in cancer survivors. Qual Life Res, 4, 523-31.

Francisca Vaz A, Marques Conde D, Siani Morais S, et al (2007). Quality of life of women with gynecologic cancer: associated factors. Arch Gynecol Obstet, 276, 583-89.

Hirabayashi Y, Miyashita M, Kawa M, et al (2007). Factors relating to terminally ill cancer patients' willligness to continue living at home during the early phase of home care after discharge from clinical cancer centers in Japan. Palliat Support Care, 5, 19-30.

Horton R (2002). Differences in assessment of symptoms and quality of life between patients with advanced cancer and their specialist palliative care nurses in a home care setting. Palliat Med, 16, 488-94.

Jocham HR, Dassen T, Widdershoven G, Middel B, Halfens R (2009). The effect of palliative care in home care and hospital on quality of life. $J H P N, \mathbf{1 1}, 119-26$.

Kelleci M(2005). Kanser hastalarının umudunun gelistirilmesine yonelik hemsirelik girisimleri. Anatolian J Psychiat, 6, 41-7.

Keskin G, Gumus BA (2011). Turkish hysterectomy and mastectomy patients depression, body image, sexual problems and spouse relationships. Asian Pac J Cancer Prev, 12, 425-32.

Knapstein SH, Fusshoeller C, Franz C, et al (2004). The impact of treatment for genital cancer on quality of life and body image-results of a prospective longitudinal 10-year study. $J$ Gynecol Oncol, 94, 398-403.

Kuzeyli Yıldırım Y (2006). Kanserli hastalarda evde bakım. In: Fadıloglu C, Ertem G (first edition). Turkey: Meta Basım Matbaacilık.

Lowdermilk DL (2006). Home care of the patient with gynecologic cancer. JOGNN, 24, 157-63.

Mantegna G, Petrillo M, Fuoco G, et al (2013). Long-term prospective longitudinal evaluation of emotional distress and quality of life in cervical cancer patients who remained disease-free 2-years from diagnosis. BMC Cancer, 13, 127.

Maughan K (2008). The effect of a clinical nurse specialist in gynaecological oncology on quality of life and sexuality. $J$ Clin Nurs, 10, 221-29.

McCorcle R, Dowd M, Ercolano E, et al (2009). Effects of nursing interventions on quality of life outcomes in postsurgical women with gynecological cancers. Psycho-Oncol, 18, 62-70.

McCorcle R, Strumpf N, Nuamah I, et al (2000). Specialized home care intervention improves survival among older post surgical gynecological cancer patients. J Am Geriatr Soc, 48, 240-49.

Mishra K (2011). Gynaecological malignancies from palliative care perspective. Indian J Palliat Care, 17, 45-51.

Molassiotis A, Brearley S, Saunders M, et al (2009). Effectiveness of a home care nursing program in the symptom management of patients with colorectal and breast cancer receiving oral chemotherapy: a randomised controlled trial. J Clin Oncol, 27, 6191-98.

Palmer P, Gillespie A (2012). Palliative care in gynaecological oncology. Obstet Gynaeco Reprod Med, 22, 123-8.

Rannestad T, Skjeldestad FE (2007). Pain and quality of life among long-term gynecological cancer survivors: a population-based case-control study. Acta Obstet Gynecol, 86, 1510-16.

Reis N, Beji KN, Coskun A (2010). Quality of life and sexual functioning in gynecological cancer patients: results from quantitative and qualitaty data. Eur J Oncol Nurs, 14, 137-46.

Sacerdoti RC, Lagana L, Koopman C (2010). Altered sexuality and body image after gynecological cancer treatment: how can psychologists help? Professional Psychol Res Pract, 41, 533-40.

Saevarsdottir T, Fridriksdottir N, Gunnarsdottir S (2010). Quality of life of symtoms of anxiety and depression of patients receiving cancer chemotherapy. Cancer Nurs, 33, 5-6.

Seavarsdottir T, Fridriksdottir N (2006). Quality of life, symptoms of anxiety and depression, and rehabilitation needs of people receiving chemotherapy for cancer at the initation of chemotherapy and three months later. Oncol Nurs Forum, 33, 469-70.

Sharifa Ezat WP, Fuad I, Hayati Y, Zafar A, Wanda Kiyah GA (2014). Observational study on patient's satisfactions and quality of life (QoL) among cancer patients receiving treatment with palliative care intent in a tertiary hospital in Malaysia. Asian Pac J Cancer Prev, 15, 695-701.

Siegel R, Jemal A, Nishadham D (2013). Cancer Statistics. CA: A Cancer J Clin, 61, 11-30.

Turgut A, Ozler A, Sak ME, et al (2012). Retrospective analysis of the patients with gynecological cancer: 11-Year Experience. JCEI, 3, 209-13.

Unsar S, Findik YU, Kurt S, Ozcan H (2007). Kanserli hastada evde bakım ve semptom yonetimi. Firat Saglik Hizmetleri Dergisi, 2, 90-108.

Xie Y, Zhao FH, Lu SH, et al (2013). Assessment of quality of life for the patients with cervical cancer at different clinical stages. Chin J Cancer, 32, 275-82.

Yajima M, Okamura K, Ijichi R, et al (2001). Differences between gynecologic cancer patients taken care for at home and those taken care for at the hospital. PUBMED, 1, 34-6.

Zimmermann C, Swami N, Krzyzanowska M, et al (2014). Early palliative care for patients with advanced cancer: a cluster-randomised controlled trial. Lancet, 383, 1721-30. 